\title{
Diferenças clínicas observadas em pacientes com dengue causadas por diferentes sorotipos na epidemia de 2001/2002, ocorrida no município do Rio de Janeiro
}

\author{
Clinical differences observed in patients with dengue caused by different \\ serotypes in the epidemic of 2001/2002, occurred in Rio de Janeiro
}

\author{
Maíla Naves Pereira Passos ${ }^{1}$, Luciana Maria Jabor Garcia Santos ${ }^{1}$, Marcelo Ricardo Reis \\ Pereira ${ }^{1}$, Clarisse Guimarães Casali ${ }^{1}$, Bruno de Paula Menezes Drumond Fortes ${ }^{1}$, Luís Ivan \\ Ortiz Valencia ${ }^{2}$, Aline de Jesus Alexandre ${ }^{1}$ e Roberto de Andrade Medronho ${ }^{1,2}$
}

\begin{abstract}
RESUM0
O objetivo deste estudo foi avaliar as diferenças clínicas e epidemiológicas das infecções causadas pelos distintos sorotipos do vírus do dengue na epidemia 2001-2002 no município do Rio de Janeiro. Foram analisados 362 casos com isolamento viral, sendo 62 do sorotipo 1,62 do sorotipo 2, e 238 do sorotipo 3. Estes casos foram notificados ao Sistema de Informação de Agravos de Notificação (SINAN) de janeiro/2001 até junho/2002. Os indivíduos infectados com 0 sorotipo 3 tiveram uma chance 6,07 vezes maior de apresentar choque em relação aos indivíduos com o sorotipo 2 (OR=6,07; IC:1,10-43,97). A chance de apresentar dor abdominal foi 3,06 maior nos infectados pelo sorotipo 3 do que naqueles por sorotipo 1 ( OR=3,06; IC:0,99-9,66). Nos infectados com o sorotipo 3, a chance de ocorrer exantema foi 3,61 vezes maior que naqueles com o sorotipo 1 ( $\mathrm{OR}=3,61$; IC:1,16-11,51) e 3,55 vezes maior que aqueles com o sorotipo 2 (OR=3,55; IC:1,28-9,97). Este estudo mostra que indivíduos acometidos pelo sorotipo 3 apresentaram dengue com maior gravidade.
\end{abstract}

Palavras-chaves: Dengue. Epidemiologia. Sinais e sintomas. Vigilância epidemiológica.

\begin{abstract}
The authors evaluated clinical and epidemiological differences among the serotypes of dengue in Rio de Janeiro's 20012002 outbreak of the disease. Out of 362 cases that had viral isolation samples, notified by the Information System for Notification Diseases ( SINAN), from January/2001 to June/2002, 62 were caused by serotype 1,62 by serotype 2 and 238 by serotype 3. In comparison with serotype 2 , an individual infected by serotype 3 had a 6.07 times higher chance $(\mathrm{OR}=6.07$; CI: $1.10-43.97)$ of presenting shock and a 3.55 times higher chance $(\mathrm{OR}=3.55 ; \mathrm{CI}: 1.28-9.97)$ of developing exanthema. When compared to serotype 1 , serotype 3 had a 3.06 times higher chance (OR $=3.06$; CI: 0.99-9.66) of causing abdominal pain and a 3.61 times higher chance of exanthema ( $\mathrm{OR}=3.61$; CI: 1.16-11.51). It was found that individuals infected by serotype 3 of the virus presented signs indicating a more severe disease.
\end{abstract}

Key-words: Dengue. Epidemiology. Signs and simptoms. Epidemiologic surveillance.

0 dengue constitui importante problema de saúde pública no mundo. 0 processo de urbanização desordenado com grande aglomeração populacional, deficiências no suprimento de água, tratamento de esgoto inexistente ou inadequado e ausência de destino adequado do lixo com 0 acúmulo de recipientes plásticos não biodegradáveis contribuem para essa situaçã $0^{1}$. Além disso, a facilidade de transporte e as intensas relações comerciais entre regiões, permitindo a entrada de pessoas infectadas em período de incubação ou mesmo do vetor em localidades indenes, e a falência dos programas de controle do mosquito favorecem 0 aumento da transmissão do dengue 238910 .

\footnotetext{
1. Departamento de Medicina Preventiva da Faculdade de Medicina da Universidade Federal do Rio de Janeiro, Rio de Janeiro, RJ. 2. Núcleo de Estudos de Saúde Coletiva da Universidade Federal do Rio de Janeiro, Rio de Janeiro, RJ.

Endereço para correspondência: Dr. Roberto de Andrade Medronho. DMP/FM/UFRJ. Av. Brigadeiro Trompowsky s/n, Cidade Universitária, $21949-900$ Rio de Janeiro, RJ. e-mail: medronho@ nesc.ufrj.br

Recebido para publicação em 11/7/2003

Aceito para publicação em 19/5/2004
} 
Sucessivas epidemias vêm ocorrendo no estado do Rio de Janeiro. Em 1986-1987, ocorreu a primeira grande epidemia com cerca de 95.000 casos registrados, sendo 49.695 no município do Rio de Janeiro, sendo detectado apenas o sorotipo 1. Durante os anos de 1990-1991, uma nova epidemia foi notificada no estado, com aproximadamente 140.000 casos notificados, 63.299 somente no município. Neste período, circulava além do sorotipo 1, 0 sorotipo 2, isolado em abril de 1990. Em 1995 ocorreram cerca de 50.000 casos no estado, dos quais 20.810 no município do Rio de Janeiro. Assim como na epidemia anterior, apenas os sorotipos 1 e 2 foram isolados. 0 Estado do Rio de Janeiro viveu em 2001-2002 a maior epidemia registrada até 0 momento, que coincidiu com 0 isolamento do sorotipo $3^{1}$. Concorreram para isto uma população totalmente susceptível, a virulência desta cepa e a elevada densidade vetorial, em função de falhas no controle do mosquito. Somente na capital ocorreram 164.559 notificações ${ }^{567}$. Cabe acrescentar que durante esta última epidemia, predominou 0 sorotipo 3, apesar de também circularem os sorotipos 1 e 2 .

0 presente trabalho visa analisar as diferenças clínicas observadas em pacientes infectados com os três sorotipos isolados na epidemia de 2001/2002 no município do Rio de Janeiro.

\section{MATERIAL E MÉTODOS}

Área de estudo. 0 município do Rio de Janeiro possui população de 5.857.904 habitantes (IBGE, 2000), exibindo uma grande importância turística, política e econômica.

Coleta e análise do material. Neste estudo, analisaramse 362 casos de dengue com isolamento viral confirmado laboratorialmente pelo Departamento de Virologia do Instituto Oswaldo Cruz (FIOCRUZ) e pelo Laboratório Noel Nutels da Secretaria Estadual de Saúde do Rio de Janeiro. Destes, 62 eram do sorotipo 1, 62 do sorotipo 2 e 238 do sorotipo 3. Estes casos pertenciam à base de dados do Sistema de Informação de Agravos de Notificação ( SINAN) , referentes às 155.217 notificações de dengue digitadas de 01 de janeiro de 2001 até 22 de junho de 2002 pela Secretaria Municipal de Saúde do Rio de Janeiro (SMS).

Análise de dados. A análise dos dados foi feita utilizando as variáveis referentes a sinais e sintomas, em função do diagnóstico final e dos sorotipos 1,2 e 3, através dos programas Epi info 6.04d e o S-Plus 2000 professional (Release 3 Copyright 1988-2000 Math Soft, Inc). Foram utilizados testes estatísticos para proporções com níveis de significância menor que $5 \%(p<0,05)$ e cálculos do odds ratio (OR) com intervalo de confiança de $95 \%$.

\section{RESULTAD0S}

Nos dois anos do estudo, observou-se predominância do sorotipo 3, principalmente em 2002, com um total de 188 casos ( Figura 1).

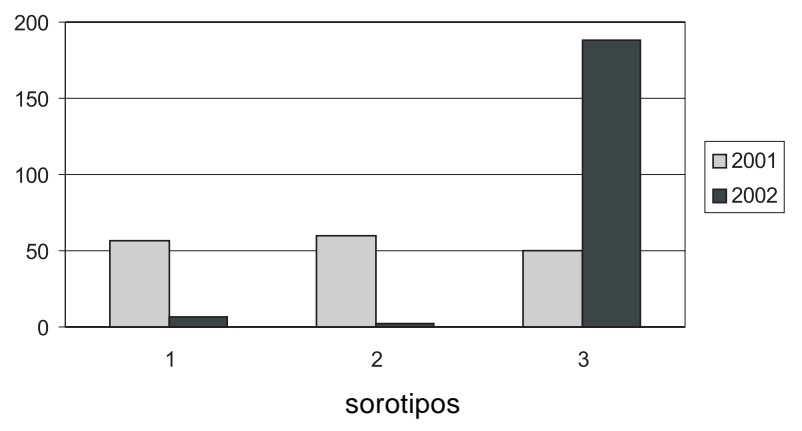

Fonte: SINAN, Secretaria Municipal de Saúde- RJ

Figura 1 - Freqüência dos sorotipos 1, 2 e 3 por ano na epidemia 2001/2002 no Município do Rio de Janeiro.

Notou-se uma predominância do sorotipo 3 tanto em relação aos casos de dengue clássico (DC) quanto de dengue hemorrágico (DH). Foram excluídos os quatro casos ( três do sorotipo 3 e um do sorotipo 1) classificados pelo SINAN como inconclusivos, ignorados ou sem informação ( Figura 2).

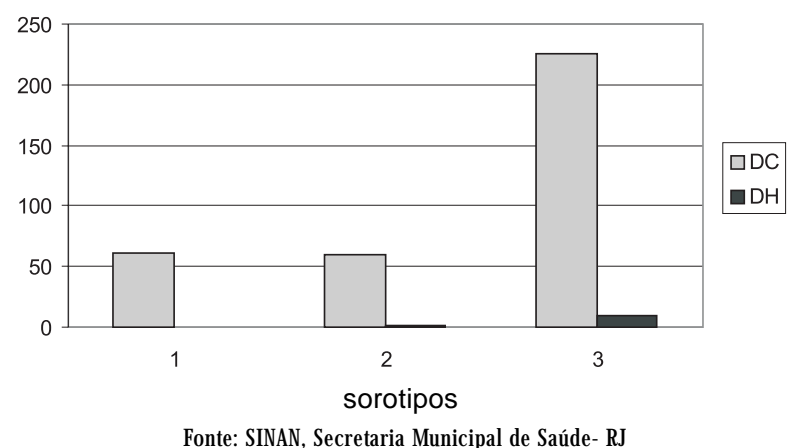

Figura 2 - Comparação entre os sorotipos 1, 2 e 3 classificados como dengue clássico ou dengue hemorrágico na epidemia de 2001/ 2002 no Município do Rio de Janeiro.

Os indivíduos com isolamento viral do sorotipo 3 tiveram uma chance 3,61 vezes maior $(\mathrm{OR}=3,61 ; 1,31-9,98)$ de apresentar exantema em relação aos com sorotipo 1 e 3,06 vezes maior $(0 R=3,06 ; 1,11-8,46)$ de apresentar dor abdominal em relação aos mesmos infectados pelo sorotipo 1, que foi utilizado como controle (Tabela 1).

Tabela 1 - Comparação entreas sintomatologias apresentadas por pacientes infectados pelos sorotipos $3 \mathrm{e} 1$, queapresentaram significância estatística.

\begin{tabular}{lrr}
\hline Sintomatologia & OR & IC 95\% \\
\hline Exantema & 3,61 & $1,31-9,98$ \\
Dor abdominal & 3,06 & $1,11-8,46$ \\
\hline
\end{tabular}

Fonte: SINAN, Secretaria Municipal de Saúde- RJ

Na Tabela 2, nota-se que a chance de haver choque é 6,07 vezes maior nos indivíduos infectados pelo sorotipo 3 que nos com 0 sorotipo 2 ( $0 \mathrm{R}=6,07 ; 1,10-43,97)$, já em relação ao exantema, há uma chance 3,55 vezes maior $(\mathrm{OR}=3,55 ; 1,28$ 9,97) de ocorrer nos indivíduos com 0 sorotipo 3, quando comparado com os infectados com o sorotipo 2 (controle).

É importante destacar que em função das manifestações hemorrágicas e óbitos terem ocorrido em pequeno número 
Tabela 2 - Comparação entreas sintomatologias apresentadas por pacientes infectados pelos sorotipos $3 \mathrm{e} 2$, queapresentaram significância estatística.

\begin{tabular}{lrr}
\hline Sintomatologia & OR & IC $95 \%$ \\
\hline Exantema & 3,55 & $1,41-8,93$ \\
Choque & 6,07 & $1,23-30,03$ \\
\hline Fonte: SINAN Secretaria Municipal de Saíde - R & &
\end{tabular}

Fonte: SINAN, Secretaria Municipal de Saúde - RJ

de casos com isolamento viral não foi possível detectar diferenças estatisticamente significantes.

\section{DISCUSSÃ0}

Na epidemia de 2001/2002, circularam os sorotipos 1, 2 e 3, com predomínio deste último sorotipo (238 casos do sorotipo 3 entre os 362 analisados) ${ }^{567}$.

Nesse estudo, a infecção pelo sorotipo 3 apresentou significativa associação com exantema em relação àquelas infecções pelos sorotipos 1 e 2. A dor abdominal esteve mais associada aos indivíduos infectados pelo sorotipo 3 do que naqueles com 0 sorotipo 1. A ocorrência de choque foi significativamente maior na infecção pelo sorotipo 3 do que no sorotipo 2. Entretanto, ressalta-se que não foi possível determinar a infecção prévia por outros sorotipos nos indivíduos analisados.

Os resultados obtidos permitiram constatar que indivíduos com o sorotipo 3 do dengue apresentam sintomatologia mais grave, sugerindo maior virulência deste sorotipo. A alta susceptibilidade da população a este novo sorotipo, infecções prévias pelo sorotipo 1 ou $2^{4} \mathrm{e}$ a virulência da cepa podem justificar a dimensão desta epidemia e sua gravidade.

Ressalta-se que em função do uso de uma base de dados secundária ( SINAN), possíveis vieses podem ter ocorrido, como 0 viés de seleção, não apenas pela provável subnotificação de casos como também pela não padronização da coleta de material para isolamento viral entre todos os casos suspeitos de dengue. Além disso, a falta de padronização na obtenção de informações referentes a todas as variáveis que constituem a base de dados do SINAN pode acarretar um viés de aferiçãa $0^{5}$.

\section{REFERÊNCIAS BIBLIOGRÁFICAS}

1. Fundação Nacional de Saúde.Vigilância Epidemiológica, Programa Nacional de Controle do Dengue. http://www.funasa.gov.br/epi/dengue/dengue0.htm, 2003.

2. Guzmán MG, Kourí G. Dengue: an update. The Lancet Infectious Diseases 2: 33-42, 2002.

3. Guzmán MG, Kourí G. Dengue and dengue hemorrhagic fever in the Americas: lessons and challenges. Journal of Clinical Virology 27: 1-13, 2003.

4. Guzmán MG, Kourí G, Valdes L, Bravo J, Alvarez M, Vazques S, Delgado I, Halstead SB. Epidemiologic studies on dengue in Santiago de Cuba, 1997. American Journal of Epidemiology 152: 793-799, 2000.

5. Miagostovich MP, Santos FB, Simone TS, Costa EV, Filippis AMB, Schatzmayr HG, Nogueira RMR. Genetic characterization of dengue virus type 3 isolates in the states of Rio de Janeiro, 2001. Brazilian Journal of Medical and Biological Research 8: 869-872, 2002.

6. Nogueira RMR, Miagostovich MP, Filippis AMB, Pereira MAS, Schatzmayr HG. Dengue Vírus Type 3 in Rio de Janeiro, Brazil. Memórias do Instituto Oswaldo Cruz 96: 925-926, 2001.

7. Nogueira RMR, Miagostovich MP, Schatzmayr HG, Santos FB, Araújo ESM, Filippis AMB, Souza RV, Zagne SMO, Nicolai C, Baran M, Texeira Filho G. Dengue in the State of Rio de Janeiro, Brazil, 1986-1998. Memórias do Instituto Oswaldo Cruz 94: 297-304, 1999.

8. Schatzmayr HG. Dengue Situation in Brazil by Year 2000. Memórias do Instituto Oswaldo Cruz 95: 179-181, 2000.

9. Tauil PL. Urbanização e Ecologia do Dengue. Caderno de Saúde Pública 17: 99-102, 2001.

10. Tauil PL. Aspectos Críticos do Controle do Dengue no Brasil. Caderno de Saúde Pública 18: 867-871, 2002.

11. Werneck GL, Almeida LM. Validade em estudos epidemiológicos. In: Medronho RA, Carvalho DM, Bloch KV, Luiz RR, Werneck GL (eds) Epidemiologia, Editora Atheneu, p.199-212, 2002. 